\title{
Translation as a Linguistics Process: A Case Study of the Concept of Equivalence in Translation TL----SL
}

\author{
$\underline{\text { Ariremako I. A }}$ A $^{1}$ Badmus-Lawal K ${ }^{2}$, M. Nazar ${ }^{3}$ \\ 1,2Department of Linguistics and Languages, Federal University Oye-Ekiti, Nigeria \\ ${ }^{3}$ Faculty of Tarbiyah, Institut Agama Islam Negeri (IAIN) Lhokseumawe, Indonesia \\ Email: Innocent.ariremako@fuoye.edu.ng,nazarm45@yahoo.com
}

\begin{abstract}
In this study, the linguistics processes guiding the concept of equivalence in translation of Source Language and Target Language are vividly discussed. When translating from one language to another, it's necessary to decode the source text and look for an acceptable translation in the target language. The main purpose of this paper is to explain the concept Equivalence in Translation to this end. The data used were drawn from some Yoruba lexical words, idioms, proverbs and figurative expressions as well as its English equivalents. According to the most authoritative research in the fields of grammar and sociolinguistics, grammatical analysis is insufficient to explain the nature of language. The results also show that knowledge of a language is a composite of knowledge of a language's structure and usage in a socio-cultural setting.
\end{abstract}

Keywords: translation; equivalence; linguistics; yoruba; process

\section{Introduction}

The interaction between and issue in the area of culture has continued to attract the interest of Yoruba and English Language Scholars. Translation is a complex process where fragile balance is achieved between the equivalence of the text translated and the linguistics means chosen. Equivalences can cause many difficulties during translation. Interest of linguists recently shifted from the traditional focus on linguistics structure of context to how texts aspects in social situations.

Despite the fact that translation has been around for a long time, equivalency is a relatively recent issue in linguistics and so its translation has not been well investigated. Exactly what we need in today's fast-paced, information-driven world. Equivalences are created by particular patterns, and understanding these patterns may substantially speed up translation.

Equivalency translation is the process of rewriting equivalence in another language. There are a number of phases involved in the reformulation process. To begin with, each word must be interpreted in order to establish equivalence. After the translation process, the arrangement of words may be altered so that a message conveyed in a given source language can be comprehended by readers. The new name and the following step create a new equivalency. You may have totally different languages for your initials if you change them. In one language, these terms are equivalent, while in another, they are translated as a series of different words.

Translators, on the other hand, are first and foremost "message couriers." As a general rule, translation is defined as the difficult process of linguistically translating a message from one language to another in order to make it understandable to the intended audience. 
This means that the translator typically just has to focus on expressing the original author's intended meaning, with no additional labour necessary.

Equivalence in translation is the emphasis of this research. The paper is broken down into seven distinct parts. The introduction, research methods, and languages are covered in sections one through three. This section covers translation, followed by equivalence, interpretation, and the conclusion in that order.

\section{Review of Literature}

Several studies have been conducted to provide empirical evidences that SL and TL have sound relation. When two languages are in contact, some of the linguistics phenomena which may in result in provision of semantic equivalence between source and target language (Adejare 2010). In his attempt to transfer meaning from one language (SL) to another (TL) by means of Universally known practice of translation. The translator faces plethora of linguistic, stylistic and even cultural problems. In this regard, Popovic (1970, p.79) confirms that "this transfer is not performed directly and it is not without difficulties". This means that the act of translation can be analysed along a range of possibilities which brings about a number of shifts in linguistics, aesthetics and intellectual values of the source text. (ST).

Tayler $(2001,2005)$ conducted two series of study to find out the influence of SL and TL equivalence. The first study was conducted to reveal the pattern of concepts of equivalence in translation. The result showed that SL and TL did not produce absolute equivalence. The secondlyrevealedthat because of the differences in SL and TL sounds and lexical items, there was no absolute or direct equivalent translation indeed.

In addition, Catford (1965), Crystal (1997), Halliday (1961) Newmark (1988) and Steiner (2010) shed more light on the possibilities of the concept of equivalence in translation. They all argued that there could not absolute one to one of SL and TL equivalence. We shall aptly look at the aspect of Yoruba- English source and target concept of translation equivalence.

\subsection{Definition}

It has been argued that language is arbitrary, by arbitrariness it is meant that there is no one to one correspondence between the form of the word and shape of the object to which the word refers (Yule, 1985, P.18). This is especially true in the case of abstract words such as advice, meaning, beauty, joy, falling, etc. this means that language is based on convention.

Language is a social process which is conditioned by the society (Abdullahi-Idiagbon, 2003). Linguistic phenomena are social because when people speak, listen, write or read, they do so in ways which are determined socially and these have social effects on the language (Fairclough, 1989).

\subsection{Languages are Different}

The arbitrariness of language is a cause for variation among language speakers of different languages. The mix the sounds of those languages different to make the words which refers to object /concept; they mix the words in the different ways to make structure patterns. 


\subsection{Language has a Means of Mirroring Humans is Perception/Thoughts}

Different people (nations) based on some factors such as belief, culture and perception accordingly, that is the nature of their expression is influenced by the nature of their perception. One may perceive a cloud as something animate then the property or the feature of a word which indicates this phenomenon maybe different from that of a language which considers cloud as an inanimate being. The ideal whiteness for somebody maybe that of show, but for another one that of a bedsheet. If so, the Yoruba speaker will say (o funfun bi eyinyin) (as white as snow), while the Englishspeaker will say "as white as bedsheet"

\subsection{Translation Concept Definition}

Converting one language (SL) to another (TL) so that the TL could convey the intend message in SL. In other words, it is a process through which the translator decoded SL and encodes his understanding of the TL form. Recent academic research has shown that translating from one language to another is one of the most complex higher order activities of the human brain. In fact, your wrong impression maybe evidenced of a good transaction: great achievements look easy.

The transaction method is dictated by the purpose of the translation. Why the best translations will always be performed primarily by a human being, in some (limited) situations, machines translation can be a useful technique, and this is likely to increase in importance overtime as this technology evolves.

\subsection{Translation as Applied Linguistics}

Linguistically, translation is a branch of applied linguistics, for the process of translation the translator consistently makes any attempt to compare and contrast different aspects of two languages to find the equivalence because applied linguistics is trying to resolve language based problem that people encounter in the real world, whether they are learners, teachers, supervisors, academics, lawyers, service providers etc.

\subsection{Equivalence Concept}

It is conventionally believed that familiarity with the SL and TL, as well as the subject matter on the part of the translator is enough for a good translation. However, if a specific linguistic unit in one language is the same intended meaning/message encoded in a specific linguistic medium in another, then these two units are considered to be equivalent. The domain of equivalent covers linguistic unit such as morphemes, words, phrases, clauses, idioms and proverbs. So finding equivalence is the most problematic stage of translation. It is worth mentioning, however, it is not meant that the translator structurally units in the two languages, that is sometimes two different linguistics units in differentlanguages carry the same functions for examples, the verb "happened"in the English sentence the happens to be happy equals to the adverb (by chance) in the Yoruba sentence, the translator, after finding out the meaning of a SL linguistic form, should ask himself/ herselfwhat the linguistic form is in another language (TL).

\section{Research Methods}

The research is a descriptive study it adopts a Natural Language processing system (NLP/NLP) systems interpret written rather than spoken language. In fact, NLP modules can be found in speech processing systems that starts by converting spoken input into text. Using lexicons and grammatical rules. NLP passes sentence, determines underlying meaning and retrieves or constructs response. This technology is mainly used to enable database to answer 
queries entered in form of a question. Newer application handles high-volume email. NLP performance can be improved by incorporating a common sense knowledge base.

\section{Discussion}

\subsection{Examples of Equivalent in English and Yoruba}

The European owl may be equal to Nigerian Owiwi symbolically: she is an Owl = Eiye owiwi lobirin yi.

Coal in English equal edudukusa in Yoruba and in English may equal (Udi Hill in Enugu) hence taking coal to Newcastle

Shoulder in English may equal Ejika in Yoruba. The blame rests on my shoulder

Bedsheet in English may equal (aso oribedi) in Yoruba: as white as bedsheet

Inch in English may equal: iwon. They knew every inch of the field

Gold in English may equal: Wura, heart of Gold

Thread in English may equal; owu in Yoruba. His life hangs by a thread

The number 9 in English equal the number esan in Yoruba. She hasdresses upto nine

The verbs walk and run in English may equal to rin and sare in Yoruba respectively. Run before one can walk.

Sometimes a multiple measuring terms in English may equal several terms Yoruba and vice versa for examples, the term depression in English equals (in astrology); (in economy) (in psychology) (in dissection) (in meteorology) and the following terms in Yoruba equal:

1. (Animal) Kingdom

2. Mountain range

3. (Ruling) dynasty

4. (Publication) series

5. Palace afin

The term "pelekipele"in Yoruba equals:

1. Class

2. Layer

3. Floor

4. Category

5. Stratum in English

Conventionally the word "ke jeun"(to eat) in Yoruba collocates with many other words, in the examples; Otutu (cold), Aga (chair), Tii (tea), Ile (ground) and onje (food)

Its equivalent, however, as far as collectability is concerned in English are:

1. To eat (for food)

2. To drink (for tea)

3. To fall (for ground)

4. To catch (for cold) respectively 
The Yoruba word collates with 1. Offisi (office), 2. Unifasiti (university), 3. Kootu (court), 4. Fakulity (faculty), 5. (public), 6. (monastery) while in English the parenthetical words are:

1. Boss

2. Chancellor

3. Magistrate

4. President

5. Superior respectively.

A compound adjective in English maybe translated in to an adjective clause in Yoruba; the teacher controlled essays were returned to the students. The initialized part is an adjective clause in Yoruba.

It is quite obvious that linguistic element which is explicit in Yoruba maybe implicit in English and vice-versa.

1. Mo ran lowo

2. I help you

3. Mo lo o

4. I used it

5. Se o Gbagbo

6. Do you believe?

7. Omo ile iwe ni

8. He is a student

9. Mo ni iwe meji

10. I have two books

Of course, the preposition lo (to) wa (come) and the word soro (talk/speech) in Yoruba have been used explicitly, which their equivalents in English are hidden or zero. On the other hand, the indefinite article á' and the plural morpheme ' $\mathrm{s}$ ' in English are explicit, but their equivalents are implicit in Yoruba.

A three-part compound word in English may be translated into single word in Yoruba: Son-in-law.

A single literary term in Yoruba maybe translated into literary terms in English: áde'(crown) to denote kinship.

\subsection{Metonymy \& Synecdoche}

Crown in Yoruba covers all types of substitution, that is, all instrument for kinship, the container for the head of a king, whole for part, effect for the cause etc., in English, however, the term synecdoche is used when part stands for whole and other accompaniments are categorised under the term 'Metonymy'.

A simple Yoruba word may be translated into a compound form in English and vice versa;

walking sticks

complete works

Agogo clock

Apo Ilewo handbag.

A noun in the genitive case in English may translates into an adjective in Yoruba

Acts of aggression 
Noun in generative case

The perfect future tense in English may be translated into present perfect or simple future tense in Yoruba

Eg I shall have written - o ye ki ntyi koweín the case of passive sentence structure, it is usually better to hold theme in the same position in both Yoruba and English.

This building was designed by a Nigerian Architect (This building by an Architect Nigerian designing did)

In this examples, this building, ile yi' has been considered to be theme and the rest of the sentence as theme. Therefore, the message has been kept the same in two languages. Do not in English sometimes equal "emase"in Yoruba

I do not agree with you sometimes "morph" in Yoruba may equal "grass" in English. The neighbour's grass is greener.

Sometimes. Due to religious, cultural, and literary factors, it is difficult to find a standard equivalent in one language for another. For example, in Nigeria, a man who has come back from a pilgrimage an Alhaji while a woman who has come back from pilgrimage is called Alhaja. Also, man and women who have paid apilgrimage to Israel are christened Jerusalem Pilgrimage (JP).

Translation and Interpretation may either be full or partial. For example:

SL- Yoruba: Kompute jeero mashini ti o lágnara

TL- English: Computer is a strong machine

From the above we can deduce that because there is no replacement for the word Computer. The translation may not be necessary be full or but partial and the word computer transliterated and not translated of course, there are other examples that can involve getting up equivalences in the target languages among the higher units on the grammatical rank scale. Since it is not bound to any particular rank. The linguistics structure of the source language is ignored and equivalent is found based on incanting it conveys.

SL Akoko ko duro denikan

TL time and tide waits for no man

SL ijafara lewu

TL A stitch in in time saves nine

SL Oba bi Olorun kosi

TL no King like God

SL oba ti waja'TL The king has passed away

SL nkan ko rogbo ni Nigeria

TL Things are not easy in Nigeria

SL Sise nigba ise ki osi sere nigba ere

TL Work while you walk and play while you play

SL Oluwa lobami se

TL God has done it for me

SL Ko si ohun ija ti a simi ti yoo le se rere

TL No weapon that is formed against me shall prosper

SL Oluwa darasimi

TL God is good to me

SL Emi o ma yin Oluwa

TL I will be praising the Lord 
From the above, it is obviously clear that free translation considers both the situational context and the cultural elements that are necessary for language interpretation. It is the highest and most sophisticated form of translation. We can see from the inferences that have been drawn in the use of source language and target language of English and Yoruba, the equivalence has clearly shown a gross inadequacy of grammatical/grammatical equivalence.

\section{Conclusion}

In this paper, we examined linguistic process: the concept of equivalence in translation involves decoding similarly, our findings from the analysis of the data in the present study revealed that translation as well as interpretation is necessitated by the fact there exists a big problem in the inter-language difficulties among tribes, nations and tongues in our world. To overcome the language related problems, some people must act as a middle man. What it means is that since after the tower of Babel event in the bible book of genesis, it became absolutely necessary for human relationship across natural bound and to use interpreters or translator to build the bridge of language. For example, for a person from Nigeria to relate and understand themselves, there has to exists a translator to link the two of them.

This paper also asserted that a translation linguistic process involves two equivalent messages between two different codes with the translator acting as a middleman between the codes. He acts as a decoder of the message in original language (source language) and the encoder of the new one.

There are several approaches by different linguistics in explicating what the concept is all about the reason for this is because translation equivalents deal with some other elements of linguistics like context of situation, grammar, mood, tenor and tone under register, deep and surface value of text. Infact, there is no way we can exhaust the discourse in this particular text.

Finally, the findings of this study have shown gross inadequacy or insufficiency of grammatical analysis of SL and TL as explanation of the nature of language as suggested by Katz (1966, p. 152).

\section{References}

Adejare, (2010), Language and style in Soyinka

Adeoye, L. (1979) AsaatiIse Yoruba, Ibadan: Ibadan university press

Cartford, J.C (1965). A Linguistic theory of Translation, Oxford University press. London.

Crystal, David(ed)(1997). The Cambridge encyclopedia of language 2ndedition, Cambridge: Cambridge University Press

Encarta English Dictionary, 2004.

Fabumi, M.A. (1972) AyajoohunIfe,Ibadan: Onibonje press

Fair Clough (1989) The sociolinguistics of language blackwell

Halliday, MAK (1961) "Categories of the Thoery of Grammar" word 1724192.

Hermans The (1999) Translation in system ; Descriptive and system. Oriented Approaches

Ibikunle, S. (1996),IweIjinle Yoruba (Apa keta) Ibadan: University Press

Katz, J.J (1966) The philosophy of language, New York; har per and Row

Newmark, Peter (1988). Approaches to Translation, Oxford: Pengamon Press

Nord Christiane (1997) Translation as purposeful activity. UK; St Jerome.

Ogunbiyi, I A. (2011) Yoruba Encyclopedia of Arabic language and linguistics, Ibadan University Press Ltd. 
Oyeleye. A.L. (1995) Translation and the African writers in English: A sample study of Achebe

Popovic, (1971), Translation techniques, Ohio USA

Tayler(2001), finding range of translation, equivalence: London, Oxford University Press.

T.F.A. and NLA. In Owolabi K (ed) 1995 English in Nigeria Essay in honour of Ayo Bamgbose, Ibadan: Group Publishers.

Schutte, Rainer and Biguent J. (eds)(1992). Theories of translation: An anthology of essays from Steiner, George Dryden to Demids, London: The University of Chicago press. Translation, Oxford (1975) after Babel: Aspect of Language and

Steiner, Peter (2010) Russian Formalism, Ithaca and London: Cornell University

Yule George (1985) The study of language. Cambridge university press 